\title{
Sobre el discurso de legitimación política de la pena estatal. Una crítica de su estructuración tradicional
}

\author{
Javier Wilenmann von Bernath*
}

\begin{abstract}
RESUMEN
El presente artículo contiene una crítica de la tradición de discusión de filosofía política designada como teoría de la pena. En él se da cuenta del vínculo entre el discurso tradicional de la teoría de la pena y una comprensión estática del Estado, bajo la cual el vínculo entre medios del Estado y la persecución de fines estatales es decisivo en la legitimación de las instituciones. El artículo muestra que una comprensión de esta clase no es conciliable con la comprensión moderna tardía del Estado y que genera, asimismo, un conformismo político contrario al espíritu crítico que la propia teoría de la pena tiende a afirmar.
\end{abstract}

Derecho penal - teoría de la pena - filosofía política - teoría del Estado

\section{On the political legitimacy of state punishment. A critique of the traditional approach to the subject}

\begin{abstract}
The paper criticizes the way in which academic discourses usually aim at discussing the political legitimacy of state punishment. It shows that the traditional language of the theories of punishment presupposes a static comprehension of the State. Such a comprehension is shown to
\end{abstract}

* Licenciado en Ciencias Jurídicas y Sociales, Universidad de Chile. Doctor en Derecho, Universidad de Friburgo, Alemania. Profesor de Derecho Penal, Universidad Adolfo Ibáñez.

Este artículo ha sido desarrollado como parte del proyecto Fondecyt $\mathrm{N}^{\circ} 1170056$ sobre "La conformación del derecho penal entre política y cultura", del que el autor es investigador responsable, siendo realizada parte de la investigación en Alemania gracias a una beca de investigación postdoctoral otorgada por la Alexander von Humboldt Stiftung. Agradezco, por ello, en primer lugar a ambas instituciones por su generosa ayuda. La investigación tuvo lugar en el Institut für Strafrecht und Rechtsphilosophie dirigido por el profesor Michael Pawlik en la Albert-Ludwigs Universität Freiburg y en la biblioteca del Max Planck Institut für ausländlische und vergleichende Strafrecht de la misma ciudad, por lo que también agradezco la generosidad de estas instituciones. Una versión preliminar de este artículo fue expuesta en el workshop "Cuestiones de filosofía penal" organizado por Enzo Solari en la Facultad de Derecho de la Pontificia Universidad Católica de Valparaíso el 13 de enero de 2017. Le agradezco al profesor Solari por su invitación y a todos los participantes por los muy valiosos comentarios recibidos en la oportunidad, los que incluso permitieron reestructurar parte del trabajo.

Artículo recibido el 26.1.2017 y aceptado para su publicación en este número el 5.1.2018. 
be incompatible with a plausible theory of the State and the traditional theories of punishment lead to political conformism in spite of pretending to be politically critical.

Criminal law - punishment theory - morality of punishment - political philosophy State theory

\section{INTRODUCCIÓN}

$\mathrm{E}$ n este artículo nos interesa examinar el potencial de rendimiento de las discusiones académicas en torno a la legitimidad política de la pena. El objeto de la crítica es, de este modo, ante todo la tradición de discusión respectiva en la academia jurídica ${ }^{1}$, pero ella es en buena medida extensible a las discusiones que tienen lugar entre filósofos prácticos referidas a la legitimidad del arreglo político "pena".

El discurso que estructura estas preocupaciones tiende a ser etiquetado como "teoría de la pena". En ese sentido, el artículo constituye una crítica a la "teoría de la pena" -como modo de designación estandarizado de discursos milenariamente reiterados respecto de la legitimidad del castigo penal- en su capacidad de rendimiento que debiera serle inmanente, a saber, dar cuenta de las condiciones de legitimidad política del castigo estatal ${ }^{2}$.

La tesis que subyace al artículo es sencilla de explicar: por su estructura misma, centrada en el análisis de la corrección moral del acto de castigar por una transgresión pasada, los modos de estructuración tradicional de la teoría de la pena (prevencionismo, retribucionismo, en sus distintas variantes) tienden a desconocer los aspectos determinantes en la evaluación de la legitimidad política de la práctica del castigo estatal. La estructuración de un sistema general de persecución y castigo por transgresiones a normas

\footnotetext{
${ }^{1}$ Tanto en la academia penal continental como angloamericana, la pregunta por la "legitimidad de la pena" tiende a ser puesta al inicio de los estudios generales acerca de derecho penal. En Alemania, ello ya era constatado por von Wächter, C.G., Lebrbuch des Römisch - Teutschen Strafrechts, reimpresión, Goldbach, 2001, p. 41, en el año 1825 y haciendo referencia a un fenómeno ya verificable 40 años antes. En el mundo anglosajón crítico, por ejemplo, Ramsay, P., "The Responsible Subject as Citizen: Criminal Law, Democracy and the Welfare State”, en The Modern Law Review, vol. 69 n 1, 2006, pp. 29ss.; y Kleinfeld, J., "Reconstructivism: the Place of Criminal Law in Ethical Life”, en Harvard Law Review, vol. 129 n $^{\circ}$ 6, 2016, pp. 1497s.). En el tratamiento monográfico o en artículos, su relevancia es asimismo retóricamente establecida mediante hipérboles. Ilustrativo Greco, L., "Verfassungskonformes oder legitimes Strafrecht? Zu den Grenzen einer verfassungsrechtlichen Orientierung der Strafrechtswissenschaft", en Brunhöber et al. (eds.), Strafrecht und Verfassung, Nomos, Baden-Baden, 2013, p. 5: "La ciencia del derecho penal es de acuerdo a su propia comprensión implícita una ciencia de la legitimidad de la pena, no solo de lege ferenda sino en primera línea de lege laga”. ¿Puede encontrarse una declaración como esta en otras disciplinas?

${ }^{2}$ El artículo se enmarca en un proyecto de mayor amplitud que pretende criticar a las prácticas de argumentación centradas en la teoría de la pena en los ámbitos en que pretende tener rendimiento y que se extienden también al control institucional de decisiones legislativas penales y al razonamiento propiamente dogmático. En todos los casos, la crítica respecto de esa capacidad de rendimiento es efectuada en artículos independientes, ya que ella implica a disciplinas académicas que no son exactamente equivalentes (aquí: filosofía del derecho y filosofía política; dogmática y teoría constitucional, en el caso del control institucional; y pura dogmática penal, en el caso de la argumentación jurídica-penal).
} 
constituidas en delitos sirve, en los hechos, a la constitución y al mantenimiento de un orden político determinado, siendo por ello influido por la configuración normativa contingente, por la estratificación particular al interior de ese orden y la distribución de bienes entre los estratos así generados y, en general, por la estructura del orden protegido. La "teoría de la pena" se ha construido, en cambio, sobre discusiones relativas a la legitimidad de una clase de acciones (el "castigo", como fenómeno moral o político); el hecho de que su justificación institucional arranque del sistema y de que legitimidad política abstracta dependa en buena medida de la legitimidad política del orden protegido es, de este modo, pasada por alta y sustituida por discusiones (más bien extrañas en un Estado democrático) sobre los "fines" que debe cumplir la pena.

La tesis en cuestión es expuesta siguiendo un orden argumentativo en tres pasos: dos pasos preliminares de clarificación y un paso final de crítica. Así, en primer lugar (II. 1), el artículo clarifica qué es aquello que es analizado en su legitimidad política, esto es, qué es, para efectos del discurso de legitimación "teoría de la pena", la "pena". La cuestión puede parecer trivial pero, como veremos en la sección II.2, tiene consecuencias cruciales para la estructuración del discurso correspondiente; precisamente por el desconocimiento del carácter de instrumento (o "realidad") político contingente es que los discursos de evaluación de la legitimidad política tienden a asumir la forma de discusiones morales o políticas de justicia sustantiva de acción. En segundo lugar (II. 2), el artículo pretende precisar los rasgos de los discursos que son sometidos a crítica en su pretensión de explicación de la legitimidad de ese objeto: no todo discurso que se designe a sí mismo como "teoría de la pena” adolece de los mismos problemas, aunque ciertos rasgos tienden a ser compartidos por una gran cantidad de exposiciones. Como nos interesa concentrarnos en la crítica a una práctica discursiva presente en distintas tradiciones académicas y no, en cambio, en la posibilidad abstracta de producir explicaciones convincentes de legitimidad política, realizar esta labor de clarificación es crucial para precisar el objeto de crítica. Finalmente, la sección III presenta la crítica misma al objeto así definido.

\section{LA PENA COMO OBJETO DE REFLEXIÓN POLÍTICA Y LA “TEORÍA DE LA PENA” COMO DISCURSO}

\section{La pena como realidad política moderna}

Tanto el derecho penal como la teoría de la pena son respuestas intelectuales -en un caso como sistematización normativa, en el otro como teoría filosófica- a un fenómeno político: la estatización monopólica de la reacción a hechos definidos como delitos o, lo que es lo mismo, la atribución de una potestad excluyente de castigar por la infracción de normas determinadas. Precisamente por ello, ambos no son comprensibles en sus dimensiones problemáticas sin tener en cuenta el fenómeno que pretenden tematizar, a saber, la práctica del castigo estatal. Entender el contexto y las condiciones en la que se inserta este fenómeno es, de este modo, crucial para evaluar las respuestas intelectuales al fenómeno. 
Pese a su apariencia de naturalidad, la pena estatal es una institución artificial esencialmente moderna ${ }^{3}$. Sería, por cierto, absurdo afirmar que todos los fenómenos que pueden ser designados como prácticas de castigo solo habrían surgido con la constitución del Estado moderno. Las prácticas de castigo anteceden al Estado e incluso a la constitución de jerarquías políticas más o menos estables ${ }^{4}$ y, por cierto, prácticas institucionales complejas de castigo con imposición jerárquica son conocidas en Occidente tanto en la Antigüedad como en la Edad Media. El Estado moderno no es de esta forma la única estructura política vinculada a la existencia de prácticas de castigo, ni siquiera la única estructura jerárquica que ha reclamado participación en ellas. Lo que, sin embargo, caracteriza la relación conceptual entre pena y Estado moderno es la administración centralizada y excluyente de las reacciones violentas lícitas frente a hechos lesivos pasados. El Estado moderno se caracteriza, de este modo, por pretender un monopolio en la reacción violenta a la realización de hechos definidos como delito en su territorio5.

${ }^{3}$ En este sentido ya Jarcke, K. E., Handbuch des deutschen Strafrechts, reimpresión, Keip Verlag, Goldbach, 1996, p. 3. Similar Achter, V., Geburt der Strafe, Vittorio Klostermann, Frankfurt am Main, 1951, p. 9s.; Gärditz, K.F., Staat und Strafrechtspflege, Ferdinand Schöningh, Paderborn, 2015, pp. 17ss. Acerca de los vínculos entre el derecho público y la modernidad véase en general Loughlin, M., Foundations of Public Law, Oxford University Press, Oxford/New York, 2010, pp. 6ss. Para evitar críticas relativas a una supuesta centralización del derecho penal en la Roma republicana e imperial -recibidas tanto en la exposición en un seminario como en el arbitraje anónimo de este artículo-, es importante dar cuenta de la posición especial que el derecho moderno estatal también asume en relación con el derecho romano: este no tenía un vínculo con una pretensión de concentración absoluta de la violencia reactiva lícita. Aquello que tiende a ser referido como "derecho penal romano" se encuentra compuesto por una superposición de funciones de distintas magistraturas, algunas de estas procedían de oficio (y, por ello, a base de aquello que hoy denominaríamos interés público o estatal) y en la gran mayoría de los casos por acción privada, como derecho de compensación de la víctima. Al respecto véase el clásico estudio de Mommsen, T., Römisches Strafrecht, Duncker \& Humblot, Leipzig, 1899, pp. 4ss, 59ss. En ciertos casos, la pena podía asimismo ser impuesta directamente por la víctima. Ejemplar a este respecto es la regulación del adulterio: su función es en buena medida excluir la condición de delito del homicidio de la mujer adúltera y de su amante por parte del marido; el homicidio era así antimonopólicamente interpretado como pena. Riggsby, A., Roman Law and the Legal World of the Romans, Cambridge University Press, New York, 2010, p. 68, le atribuye esta característica a la limitada capacidad de acción del poder político romano.

${ }^{4}$ Para mencionar casos bien investigados y ampliamente conocidos, basta con hacer referencia aquí a las prácticas descentralizadas de castigo presentes en los pueblos germánicos: la privatización del conflicto y de la reacción al delito como un derecho del afectado, su familia o su Sippe no tienen relaciones con nuestras prácticas burocráticas, centralizadas y monopólicas de castigo por parte del Estado. Sobre las prácticas de castigo de los germanos véase solo Achter, V., Geburt der Strafe, Vittorio Klostermann, Frankfurt am Main, 1951, p. 11ss.; Schmidt, E., Einführung in die Geschichte der deutschen Strafrechtspflege, 2. Edición, Vandenboeck \& Ruprecht, Göttingen, 1951, pp. 21ss.; Rüping, H. y Jerouscheck, G., Grundriss der Strafrechtsgeschichte, 5. Edición, C.H. Beck, München, 2007, Nm. 5ss. El caso históricamente más relevante se ve constituido por el derecho de guerra del agraviado (la Fehde), el que tuvo influencia en la constitución política medieval hasta el siglo XIII o XIV. Respecto de su relevancia política y la enorme diferencia que ello implica con nuestro mundo político véase el clásico estudio de Brunner, O., Land und Herrschaft, 5. Edición, Wissenschaftliche Buchgesellschaft, Darmstadt, 1984, pp. 11ss., 41ss.

${ }^{5}$ Locus classicus: Weber, M., Wirtschaft und Gesellschaft, editado por Johannes Winckelmann, 5. Edición, Mohr, Tübingen, 1980, pp. 29; 821ss. La idea del monopolio de la violencia legítima no se refiere -y esto tiende a ser mal entendido- a la prevención de la violencia por otro, sino a la reacción violenta a la violencia ya acaecida. Los ejemplos que típicamente se entregan para construir excepciones (ante todo: legítima 
Radicalizado: Estado solo hay allí donde la violencia reactiva se encuentra generalmente prohibida y esa prohibición puede ser impuesta con cierto éxito por la entidad (personal o ideal) que la reclama, con independencia del estamento o de la pertenencia social de las partes, siendo reemplazadas todas las formas de reacción frente a la injuria pasada por el monopolio en el castigo de delitos. La pena es así dependiente del Estado, pero el concepto de Estado es dependiente del concepto de pena ${ }^{6}$ : la circularidad solo manifiesta aquí la interdependencia histórica de ambas instituciones. Con ello, del mismo modo en que desde mediados del siglo XX la utilización del concepto de Estado se tiende a reservar para la designación del dominio político territorial moderno - no siendo extensible a otras formas de organización jerárquica ${ }^{7}-$, el concepto de pena se vincula conceptualmente a la realidad política que posibilita tanto la atribución a una misma unidad de imputación de todo castigo penal, así como la exclusión fáctica (más o menos efectiva) de las reacciones a delitos.

La pena es de este modo un producto de la modernidad ${ }^{8}$; ella es condición y resultado de la concentración del poder represivo en un individuo (el soberano) o en una

defensa) nunca han sido contradictorios con sino más bien confirmatorios de las pretensiones del Estado moderno. Recientemente Husak, D., "Does the State have a Monopoly to Punish Crime?", en Flanders, C., y Hoskins, Z. (eds.), The New Philosophy of Criminal Law, Rowman \& Littlefeld, London, 2016, pp. 99ss., ha argumentado contra la asunción de que el Estado posee un monopolio del castigo. Su argumento, como es usual en la filosofía de la pena anglosajona reciente, asume una definición esencial de castigo (punishment): es constitutiva de castigo cada acción que tiende a la estigmatización por la realización de acciones pasadas a partir de la irrogación de algún daño (hardship). De acuerdo con Husak, no sería difícil, sin embargo, encontrar prácticas jurídicamente reconocidas de castigo en la sociedad civil. El castigo de una deportista que se ha dopado durante su carrera tiende a ser exigido y esperado de las asociaciones deportivas, con completa independencia de que no se trate de organismos estatales. El argumento de Husak pasa por alto el punto central relativo al discurso referente al monopolio de la violencia represiva legítima del Estado. Lo relevante no es la pretensión de castigo que tengan acciones civiles -el Estado ciertamente no pretende prohibir esto-, sino la definición general de ciertas acciones como violencia prohibida, cuya irrogación represiva es completamente reservada al Estado. En el ejemplo de Husak: el castigo de la deportista mediante desconocimiento de logros deportivos no se encuentra definido como violencia reservada al Estado. Si, en cambio, la asociación deportiva reaccionara con la privación de libertad de la deportista, esto sería sin dudas valorado como privación de libertad punible por parte del Estado. La conversión de acciones que se definen como violencia prohibida en acciones jurídicamente reconocidas se encuentra reservada al Estado. El punto ya era advertido en la distinción ya trabajada por Jellinek, G., Allgemeine Staatslehre, pp. 428ss., entre violencia disciplinaria no reservada al Estado y violencia de dominación (Herrschergewalt) reservada a este.

${ }^{6}$ Así también, por ejemplo, Hälschner, H., Das gemeine Deutsche Strafrecht. Band I: Die allgemeinen strafrechtlichen Lehren, reimpresión, Keip Verlag, Goldbach, 1997, p. 2. Lo anterior no quiere decir que no sea teóricamente pensable el Estado moderno sin prácticas centrales y exclusivas de castigo (la pena); es posible que en un mundo político-social alternativo la misma prestación -la exclusión de la violencia reactiva privada- pueda ser obtenida por otros medios que complementen a la violencia preventiva estatal. Esta es la pretensión de movimientos como la justicia restaurativa y no pretendo discutir aquí la posibilidad de su eficacia. Agradezco a Rocío Lorca por hacerme ver la necesidad de clarificar este punto.

7 Ilustrativo Böckenförde, E.W., Recht, Staat, Freibeit, edición extendida, Frankfurt am Main: Suhrkamp, 2006, p. 92, quien califica como “determinante del espíritu de su generación” el cambio en el uso del concepto de Estado.

${ }^{8}$ Así también Gärditz, K.F., Staat und Strafrechtspflege, Ferdinand Schöningh, Paderborn, pp. 18s. Acerca de la estatización del derecho y de la administración de justicia véase en general Reinhard, W., Geschichte der Staatsgewalt, C.H. Beck, München, 1999, pp. 291ss. 
entidad irreal que se reconozca en la construcción de ciertas acciones institucionales (el Estado) en un territorio determinado. De este modo, el vínculo entre realidad política moderna y pena puede ser demostrado de modo relativamente sencillo no solo por referencia al monopolio de la violencia reactiva lícita, sino también al reflexionar pertinente a las atribuciones de sentido que debemos realizar para reconocer un acto como "pena".

El primer punto es relativamente evidente: nuestras prácticas punitivas implican la exclusión de poderes concurrentes al Estado en la reacción a los delitos, lo que fácticamente solo puede tener lugar asumiendo una organización burocrática más o menos extensa, poder de imposición de las decisiones burocráticas y, con ello, el desarrollo de la soberanía (estatal) en un territorio extenso 9 . Todas estas son condiciones que, al menos en el mundo posantiguo, solo se encuentran presentes desde la modernidad temprana.

Pero también la reconstrucción unitaria de autoría de actos institucionales tales como "imposición” o "ejecución” de la pena requiere de prestaciones sintéticas propiamente modernas: la pena presupone la atribución de la imposición y ejecución del castigo, cualquiera que sea la identidad natural del funcionario que la impone o ejecuta y sin importar el lugar del (a veces extenso) territorio en el que se encuentre, a una misma unidad de imputación (el Estado). Sin el conjunto de prácticas simbólicas y coactivas que permiten la generación de ese centro de imputación, aquello que denominamos derecho penal sería radicalmente distinto ${ }^{10}$.

Pese a esta condición esencialmente moderna del derecho penal -en esto, su pertenencia al moderno derecho público es evidente-, este se encuentra vinculado internamente con los modos de reconstrucción de las relaciones privadas provenientes del derecho civil romano (ya que asume una función regulativa de relaciones privadas), con las prácticas y estructuras conceptuales del derecho canónico y, en algo que lo aleja todavía más de la modernidad, con prácticas que pueden ser ubicadas en el mundo no institucional de la cultura. El derecho penal es así parte del mundo institucional público moderno, pero vincula a ese mundo prácticas preestatales y preinstitucionales.

Como nuestro objeto de estudio aquí es la teoría de la pena como discurso privilegiado de tematización intelectual de este fenómeno, no nos interesa en este contexto entender más de cerca las condiciones históricas que hicieron posible su aparición e imposición casi global, sino las tareas intelectuales ligadas a un hecho históricamente generado.

\footnotetext{
${ }^{9}$ Así también Garland, D., The Culture of Control, Oxford University Press, Oxford/New York, 2001, pp. 29ss. En tendencia también Kaspar, J., Verbältnismäßigkeit und Grundrechtsschutz im Präventionsstrafrecht, Nomos, Baden-Baden, 2014, pp. 27s.

${ }^{10}$ Un modo usual de plantear un problema similar consiste en intentar explicar la estatalidad del castigo dando cuenta del sentido que debe expresar un castigo penal: la ejecución de un acto violento debe verse como expresión de reproche legítimo y ello solo es posible si se une a un acto de comunicación público. Afirmaciones de esta clase son fácilmente reconocibles tanto en la tradición "idealista” alemana del siglo XIX como en el "moralismo jurídico" anglosajón actual. Así, por ejemplo, von Hirsch, A. y Ashworth, A., Proportionate Sentencing, Oxford University Press, Oxford/New York, 2005, pp. 29ss. Esto es, por cierto, correcto. Pero es importante ver que plantear las cosas así es partir, por así decir, por el final. Epistemológicamente considerado, el reconocimiento de esa "valoración pública” implica la capacidad sintética de reconocer la acción en cuestión en relación con un objeto ontológicamente existente solo en esas acciones.
} 
En tanto hecho institucional artificial, el interés normativo relativo a este no es solo de sistematización y sujeción a reglas determinadas -esto es, constituirlo en derecho penal-, sino que también se encuentra sujeto a crítica política. ¿Por qué organizamos nuestras relaciones sociales de modo tal que castigamos centralmente por la realización de hechos definidos como delito? La respuesta puede aquí tender a reflejar una naturalización inicial del fenómeno a causa de lo cotidiano que se nos aparece. Vivimos, después de todo, en un mundo político en que parte de la estabilidad de las relaciones sociales parece verse asegurada por la existencia del Estado soberano y de sus prácticas monopólicas de castigo. La libertad de los miembros de las comunidades políticas, en el sentido de no ver constantemente amenazados sus planes de vida por la posibilidad de la violencia privada, dependería así del Estado. Pero incluso si concedemos el punto en relación a que Estado y prácticas de castigo estatal son condiciones de la seguridad que conocemos, sigue siendo necesario reconocer que su estabilidad depende de violencia y concentración del poder, por lo que simplemente aceptar el fenómeno no parece ser una actitud intelectual adecuada ${ }^{11}$.

La práctica de discusión "teoría de la pena" asume este desafío: si bien quienes toman parte de ella no siempre expresan conciencia del grado de artificialidad del fenómeno que tematizan, si algo caracteriza a la práctica en cuestión es la asunción del carácter problemático de su objeto de discusión y, a partir de ello, de la necesidad de entregar una explicación legitimatoria, en lo posible con potencial crítico, respecto de ese fenómeno. El modo en que ella encara este desafío es algo que revisaremos con más detalle en la próxima sección.

\section{La teoría de la pena como discurso de filosofía moral o de filosofía política}

Como hemos visto, el discurso académico que ha pretendido hacerse cargo de la preocupación política en torno a la práctica punitiva es designado como "teoría de la pena”. Su preponderancia puede notarse, como hemos visto, inmediatamente en la literatura penal, en la que prácticamente toda exposición general del derecho penal asume en algún capítulo introductorio que debe exponer y, en lo posible, tomar partido por alguna de las posibles explicaciones al fenómeno del castigo que nos son conocidas por milenios: ¿se castiga simplemente porque el delincuente realizó una acción incorrecta que, por ello, merece castigo? ¿O el castigo tiene por objeto prevenir la realización de delitos futuros?

Contra lo que sugiere la consideración de las teorías de la pena como un discurso teórico, la pregunta que anima a la discusión no es, sin embargo, siempre la misma. A este respecto uno puede distinguir dos clases de acercamiento: un acercamiento moralizante y un acercamiento político.

${ }^{11}$ Acerca de las actitudes intelectuales frente al fenómeno del Estado, lúcido ya Jellinek, G., Allgemeine Staatslebre, 3. Edición, Wissenschaftliche Buchgesellschaft, Darmstadt, 1960, pp. 184ss. 
El acercamiento moralizante asume que el problema de la pena se encuentra en su carácter de castigo. El castigo sería así una clase de acción moralmente problemática que necesitaría de justificación, ya que se responde a un mal con otro mal, o se afectan derechos morales del castigado, etc. De plantearse una respuesta convincente a la justificación moral del castigo como una acción correcta o, al menos, permitida, entonces se respondería en lo esencial a las preguntas legitimatorias que plantearía la pena. Este modo de acercamiento es especialmente popular en la actualidad en la literatura anglosajona, la que de la mano de Anthony Duff y Michael Moore ha pasado a desplazar a las dominantes explicaciones utilitaristas concernientes al castigo estatal, dando cuenta de la (elocuentemente designada) morality of punishment ${ }^{12}$. La teoría de la pena asume, bajo esta comprensión, que ella es constitutiva de un caso especial de filosofía moral. La explicación de las razones y condiciones en las que un castigo puede ser moralmente correcto (o incorrecta) - la idea de merecimiento- es puesta así como centro de la explicación de la legitimidad de la pena estatal ${ }^{13}$.

Bajo el acercamiento político, en cambio, la asunción básica es la necesidad de legitimación de la coacción estatal en general y del establecimiento de una relación de dominación al menos aparente en este, así como de las razones por las que un castigo puede justificarse dentro de la relación en cuestión. La teoría de la pena es así vista como un caso especial de filosofía política o, en la fórmula original de la filosofía moderna, de filosofía del Estado. Como la pena es construida aquí como un caso calificado de coacción estatal o, en una descripción alternativa, como un elemento constitutivo de la relación "Estado-ciudadano", la teoría de la pena que se entiende a sí misma como

\footnotetext{
${ }^{12}$ Acerca del proceso de "moralización" de la teoría de la pena en el mundo anglosajón, véase Thorburn, M,, "Criminal Law as Public Law", en Duff, R. A. y Green, S. (eds.), Philosopbical Foundations of Criminal Law, Oxford University Press, Oxford/New York, 2013, pp. 24ss.; Duff, R.A. "Penance, Punishment and Community", en Punishment and Society, vol. 5, 2003, pp. 297s.; Tonry, M., "Punishment", en el mismo (ed.), The Oxford Handbook of Crime and Criminal Justice, Oxford University Press, New York, 2011, p. 103.; y Brudner, A., Punishment and Freedom, Oxford University Press, Oxford/New York, 2009, p. x. Críticos como aquí sobre el desconocimiento del carácter político de la pregunta por la pena. Murphy, J.G., "Does Kant Have a Theory of Punishment?", en Columbia Law Review, vol. 87 n 3, 1987, pp. 510s.; Ramsay, P., "The Responsible Subject as Citizen: Criminal Law, Democracy and the Welfare State", en The Modern Law Review, vol. 69 n 1, 2006, pp. 29ss.; Binder, G., "Punishment Theory: Moral or Political”, en Buffalo Criminal Law Review, vol. 5, 2002, pp. 321ss. Binder va, sin embargo, más allá de la pregunta por la justificación del castigo estatal y pretende vincular la cuestión con otras prácticas de castigo, cuyo carácter político no es claro. Bajo influencia de la literatura anglosajona, en la tradición continental puede advertirse un planteamiento similar ("moralizante") por ejemplo en Zürcher, T., Legitimation von Strafe, Mohr Siebeck, Tübingen, 2014, pp. 1.s, 9ss.

${ }^{13}$ Así también Chiao, V., "What is the Criminal Law for?", en Law and Philosophy, vol. $35 \mathrm{~N}^{\circ} 2,2016$, pp. 148ss.; Thorburn, M,, "Criminal Law as Public Law”, en Duff, R. A. y Green, S. (eds.), Philosophical Foundations of Criminal Law, Oxford University Press, Oxford/New York, 2013, pp. 26ss. Respecto de las razones que llevan al discurso legal y filosófico a centrarse en reflexiones de esta clase, lúcido Tonry, , M., "Punishment", en el mismo (ed.), The Oxford Handbook of Crime and Criminal Justice, Oxford University Press, New York, 2011, pp. 95ss. Es importante no pasar por alto que la idea de que preguntas de filosofía política son simples preguntas de justicia sustantiva no es exclusiva a la teoría de la pena, sino que (al menos desde la Teoría de la Justicia de Rawls) se trata de una tendencia fácilmente identificable en la filosofía política en general. Así Waldron, J., Political political theory, Harvard University Press, Cambridge/London. 2016, pp. 4s.
} 
un subdiscurso de la filosofía del Estado asume que debe derivar sus fundamentos de las mismas condiciones sustantivas que explican la legitimidad del poder soberano del Estado en general ${ }^{14}$.

En este punto es importante aclarar dos prejuicios que probablemente surjan en el lector que conozca con mayor o menor precisión el debate pertinente a la teoría de la pena. El primer prejuicio se refiere al modo en que las tradicionales clasificaciones de las teorías de la pena se dejan relacionar con la distinción anterior. A grandes rasgos es probable que se asuma que las teorías retributivas son en general teorías moralizantes y que las teorías preventivas son teorías políticas. Pero si bien es posible apreciar una tendencia en ese sentido, no hay necesidad conceptual de que ello sea así. Las teorías preventivas son también teorías moralizantes si asumen que la justificación de la pena debe ser realizada simplemente demostrando la idoneidad de la acción culturalmente identificable como castigo para conseguir fines valiosos, sin reflexionar por las implicancias políticas del hecho de que se trate de una práctica estatal. Del mismo modo, las teorías retributivas pueden ser teorías políticas cuando centran su discurso en la explicación de la justificación del carácter estatal de la pena y de la relación de dominación de la que participa.

El segundo prejuicio se refiere a la preferencia por una de las alternativas que pueda advertirse en la exposición anterior. Teniendo en cuenta que la exposición anterior asume, en lo esencial, que el acercamiento moralizante a la práctica punitiva es incorrecto porque se desentiende de un punto esencial en la explicación de la legitimidad del castigo, probablemente pueda aquí surgir la impresión de que solo el acercamiento político puede ser correcto. Este prejuicio del lector es también parcialmente correcto, pero en este punto no nos interesa resaltar solo la necesidad de abarcar la inserción de la práctica punitiva en un contexto político artificial al realizar discursos teóricos legitimatorios atinentes al derecho penal, sino también un rasgo que la teoría de la pena que se entiende a sí misma como caso especial que filosofía del Estado comparte con el acercamiento moralizante: la idea de que la legitimación solo puede derivar de la entrega de un fundamento sustantivo al castigo penal en sí, esto es, de que debe explicar las razones por las que el castigo estatal permite en sí obtener prestaciones que lo justifiquen ${ }^{15}$.

${ }^{14}$ Entre nosotros acertado Mir Puig, S., Estado, pena y delito, BdeF, Montevideo/Buenos Aires, 2006, p. 95. Recientemente también crítica del acercamiento puramente moral Lorca, R., "The Presumption of Punishment: A Critical Review of its Early Modern Origins", en Canadian Journal of Law E Jurisprudence, Vol. $29 \mathrm{n}^{\circ}$ 2, 2016, pp. 385ss.

${ }^{15}$ Un ejemplo elocuente de estas limitaciones puede encontrarse en la exhortación de Duff y los otros coinvestigadores en su proyecto de criminalización a dejar de pensar la teoría de la pena como una cuestión puramente moral y asumir su carácter político, esto es, la necesidad de anclar el pensamiento teórico penal en una "teoría del Estado". Véase Duff et al., "Introduction. Towards a Theory of Criminalization?", en los mismos (eds.), Criminalization. The Political Morality of the Criminal Law, Oxford University Press Oxford/ New York, 2014, pp. 5s. Si bien la exhortación parece coincidir con la crítica expuesta en nuestro diagnóstico, la ilustración del modo en que debiera ser politizado el discurso de la teoría de la pena debiera producir de inmediato frustración: la invocación como ejemplos de pensamiento "político" de la pena de los trabajos de Philipp Pettit y John Braithwaite, por ejemplo, muestra que "político" quiere decir aquí "de justicia sustantiva” en relación con la pregunta acerca de si la pena can be justified in principle, Tadros, V., The Ends 
Asumamos, a partir de lo anterior, que solo son interesantes para nuestros efectos teorías que asuman la condición política del castigo penal, pero que ellas deben tener una orientación sustantiva a las explicaciones de legitimidad (esto es: sin establecer vínculos fuertes con procedimientos legitimatorios) para calificar como teoría de la pena y entrar, por ello, en nuestra crítica. Esto nos lleva a centrar nuestra crítica en teorías de la pena que deben cumplir dos condiciones: (i) ser políticas (= expresivas de una filosofía del Estado y no solo de filosofía moral), ya que de otro modo no abarcan el centro de interés legitimatorio de la práctica punitiva; y (ii) asumir una justificación sustantiva de legitimidad, ya que de otro modo no califican en lo que definimos ${ }^{16}$, para estos efectos, como teoría de la pena.

\section{Características centrales de la teoría de la pena como filosofía política aplicada}

Reconstruida en relación con la filosofía del Estado, de la que el acercamiento que nos interesa formaría parte, la pena es justificada a partir de una demostración de que ella es necesaria a la realización de un fin que a su vez justificaría en general la existencia de la relación de dominación que constituye al Estado. Así, del mismo modo en que el Estado encontraría su justificación en la concesión de seguridad y, con ello, de libertad externa ${ }^{17}$, la pena podría ser justificada por posibilitar la realización de ese fin ${ }^{18}$. Como la prestación obtenida por medio del precio que se paga -expresado de modo incompleto: verse sometido a la posibilidad del castigo estatal; mejor: someterse a la dominación estatal que incluye el reconocimiento de la potestad excluyente de castigar- se vería sobrecompensada por el beneficio obtenido, la pena sería una institución racional y, con ello, políticamente justificable. Todos estos rasgos se encuentran presentes en la siguiente afirmación ilustrativa de Peter Ramsay:

Penal laws are commands or threats made by a political sovereign with a monopoly on legitimate coercion. The sovereign coerces legitimately only when it coerces in the public interest. (...) In a distinctively liberal political community that shared interest will be individual freedom. A liberal political theory of punishment must, therefore, show how the form and content of the public wrongs that comprise the

\footnotetext{
of Harm. Oxford University Press, Oxford/New York, 2011, p. 2. La teoría de la pena política sigue siendo teoría de la justicia abstracta.

${ }^{16}$ El definimos no es expresivo de un poder arbitrario del autor, sino que pretende dar cuenta que la literatura penal (y filosófica) en general construye sus discursos a los que denomina teoría de la pena siguiendo esta estructura. La utilización de una limitación definitoria no tiene por objeto, por ello, más que dar cuenta que la crítica se refiere solo a los discursos que asuman las características de sustantividad.

17 Sobre la construcción de un "fundamento último" del Estado en la seguridad véase la todavía instructiva exposición de Jellinek, Allgemeine Staatslehre, 3. Edición, Wissenschaftliche Buchgesellschaft, Darmstadt, 1960, pp. 207ss.

18 Pertinente al carácter dominante de este acercamiento Zabel, B., "Die ordnungspolitische Funktion des Strafrechts", en Zeitschrift für die gesamte Strafrechtswissenschaft, vol. $120 \mathrm{n}^{\circ}$ 1, 2008, pp. 89ss. También Greco, L., Lebendiges und Totes in Feuerbachs Straftheorie, Duncker \& Humblot, Berlin, 2009, pp. 17s.
} 
substantive criminal law serve rather than undermine the liberal public reason of individual freedom ${ }^{19}$.

La definición de Ramsay es instructiva de todos los elementos que caracterizan a una buena teoría (tradicional) de la pena: ella asume, en primer lugar, que se trata no solo de la justificación de una clase de acciones, sino de una relación de dominación de la que depende esa acción; pero acepta al mismo tiempo que la única clase de respuesta convincente a esta pregunta es la demostración de la racionalidad de la realidad que se trata de criticar por medio de la demostración de su carácter racional en sí, esto es, como acciones justas provechosas en sí. Esta es una clase de acercamiento fácilmente reconocible en la tradición continental ${ }^{20}$.

Debido al acercamiento sustantivo a la justificación de fenómenos políticos, la filosofía del Estado que se encuentra en la base de la teoría de la pena necesita asumir una comprensión estática de este. El Estado es así visto como una entidad cuya justificación es relativamente fija porque su identidad es, en sus aspectos esenciales, fija. El modo más tradicional (y, al mismo tiempo, más convincente) de producir una explicación de esta clase puede denominarse (parcialmente) hobbesiano ${ }^{21}$ : el Estado es el modo de asociación y delegación de poder soberano necesario a la superación de un estadio de inseguridad de otro modo insuperable ${ }^{22}$. Sus instituciones se orientan, por ello, a la configuración necesaria para proveer de seguridad respecto de intereses preestablecidos. Su legitimidad provendría del hecho de su necesidad para la provisión de seguridad: como en un estado sin seguridad (ie: estado de naturaleza) no se tiene, en lo esencial, nada, la ganancia sería infinitamente superior al sacrificio y el arreglo sería con ello en sí legítimo.

Una fundamentación de esta clase tiende a ser hecha extensible a las instituciones que constituyen parte de la identidad de esta comprensión del Estado, como la pena ${ }^{23}$.

${ }^{19}$ Ramsay, P., “The Dialogic Community at Dusk”, en Critical Analysis of Law, vol. 1 n 2, 2014, p. 317.

${ }^{20}$ Pese a que, por ejemplo, en Kant el modo de correlación entre el derecho como instrumento político (coordinación libre de ámbitos de libertad) y la teoría de la pena no es claro, la contribución central en una estructuración de esta clase del discurso, al menos para la academia penal, viene de Feuerbach. Véase Feuerbach, P.J.A., Lebrbuch des gemeinen in Deutschland gültigen peinlichen Rechts, reimpresión, Scientia Verlag, Aalen, 1986, pp. 36s.; el mismo, Revision der Grundsätze und Grundbegriff des positiven peinlichen Rechts, reimpresión, Scientia Verlag Aalen, 1966, pp. 38ss. La dependencia de la teoría de Feuerbach no de consideraciones instrumentales en torno a la pena sino de una teoría del Estado ha sido claramente advertida por Naucke, W.,"Fragen an Feuerbachs Staatsbegriff”, en Gröschner, R. y Haney, P. (eds.), Die Bedeutung P.J.A. Feuerbachs (1775-1833) für die Gegenwart, (Franz Steiner Verlag, Wiesbaden, 2003, pp. 41 ss.

${ }^{21}$ Califico de "parcialmente" hobbesiano este acercamiento, ya que si bien la obra misma de Hobbes se encuentra llena de explicaciones sustantivas de las instituciones jurídicas -así la pena sería necesaria para educar a la obediencia al soberano-, el modo de estructuración del poder es completamente positivo e institucional: delegación completa de todas las facultades (al menos en lo que no respecten a la muerte del ciudadano) de determinación de lo obligatorio al soberano, como estándar óptimo de conservación de libertad y seguridad.

${ }^{22}$ Respecto de la extensión de este modo de argumentación véase en general Zabel, B., "Die ordnungspolitische Funktion des Strafrechts", en Zeitschrift für die gesamte Strafrechtswissenschaft, vol. 120 $\mathrm{n}^{\circ} 1,2008$, p. 89ss.

${ }^{23}$ Hobbes, T., Leviathan, J.M. Dent \& Sons, London, 1914, p. 164. 
Como el discurso de justificación general del Estado es, sin embargo, demasiado abstracto para explicar de inmediato la configuración de una institución específica, la filosofía del Estado tendía a precisar las conclusiones por medio de su concreción en definiciones de objetivos estatales (teoría de los fines del Estado). La producción de una explicación de su legitimidad depende así de la demostración de su carácter necesario al cumplimiento de uno de esos fines esenciales (la seguridad); la toma de medidas que excedan o que no tengan vinculación con lo necesario solo podría asumir una explicación por poder, pero no debiera ser merecedora de reconocimiento ${ }^{24}$. La teoría de los fines de la pena es así una manifestación de este modo de razonamiento.

Aunque es probable que por razones ideológicas no siempre se esté dispuesto a reconocer los méritos de este modo de razonamiento - parece tratarse de un modo de argumentación asociado o bien a un liberalismo ingenuo o bien a un utilitarismo demasiado sencillo-, su poder de convicción es indudable y, como reconstrucción general de la fundamentación sustantiva del poder represivo estatal, sigue siendo un modo de pensamiento al menos estructuralmente hegemónico ${ }^{25}$ : no solo la teoría de la pena, sino también la cultura en general, asocia el derecho penal al otorgamiento de seguridad.

\section{LA INSUFICIENCIA DE LA TEORÍA DE LA PENA COMO DISCURSO CRÍTICO POLÍ́TICO}

La crítica respecto de lo convincente que resultan los discursos dominantes de reflexión en torno a la legitimidad política de la pena que desarrollaremos se refiere, en lo esencial, a dos puntos: ella necesita asumir una identidad más o menos fija del Estado y de los fines que persigue (1) y ella requiere asumir que la legitimidad de los instrumentos del Estado es independiente de la legitimidad del orden estatal (2).

${ }^{24}$ Más allá del caso de Feuerbach, en la literatura del siglo XIX, especialmente nítidos en la adopción de una estructura de argumentación de esta clase von Grolman, K., Grundsätze der Criminalrechtswissenschaft, reimpresión, Keip Verlag, Goldbach, 1996, pp. 4ss.; von Mohl, R., Die Polizei-Wissenschaft nach den Grundsätzen des Rechtsstaates. Dritter Band: System der Präventiv-Justiz, 3. Edición, Verlag der H. Laupp'schen Buchhandlung, Tübingen, 1866, pp. 9ss.; Bauer, A., Lebrbuch des Strafrechts, reimpresión, (Goldbach: Keip Verlag (Vandenhoeck und Ruprecht), 1996, pp. 25ss.; el mismo, Die Warnungstheorie, reimpresión, Keip Verlag Goldbach, 1996, pp. 1ss. Pese a la equivalencia estructural, prácticamente todos estos acercamientos asumen una definición del estado de cosas cuya protección es necesaria -el estado civil o de derecho- que tiene un contenido sustantivo mucho más denso que en el caso de Hobbes. Eso no le quita su equivalencia estructural: se sigue tratando de la entrega de una definición estática del Estado y de una construcción de una relación de necesidad con la pena para su mantenimiento.

${ }^{25}$ Este carácter hegemónico en lo relativo a las teorías de la pena es también constatado por Greco, L., Lebendiges und Totes in Feuerbachs Straftheorie, Duncker \& Humblot, Berlin, 2008, pp. 17s. 


\section{La asunción de los fines fijos del Estado; el Estado como entidad política}

La primera crítica debiera ser fácilmente comprensible tras reflexionar brevemente referente a los presupuestos conceptuales de una teoría de la pena construida sobre las dos características descritas en la sección II. Las teorías de la pena asumen que la contribución al mantenimiento o confirmación de un estado de cosas valioso es aquello que justifica a la pena. Las teorías de la pena de hecho tienden a diferir entre sí y, por ello, a discutir entre ellas, ante todo en relación con el modo en que ese estado de cosas puede y debe ser mantenido por medio de la práctica punitiva (intimidación, confirmación, neutralización de sujetos que se revelen como peligrosos, etc.). Por ahora no nos interesa concentrarnos en esa discusión instrumental, sino más bien en aquello que asumen las teorías de la pena al proceder así: que el problema político de la pena no se encuentra en la definición del estado de cosas a ser producido o mantenido sino más bien en cómo ello puede tener lugar ${ }^{26}$.

Pese a que el estado de cosas valioso tienda a ser designado en relación con intereses individuales, se trata en realidad del aseguramiento de expectativas (creíbles) respecto de esos intereses individuales. Esto es obvio desde el momento en que, a diferencia de la acción directamente preventiva del Estado (policía e inteligencia), la pena siempre actúa después de que se ha producido una acción que se quiere evitar y en general, después de que se han afectado intereses individuales o colectivos. Las excepciones se encuentran en los casos de adelantamiento de la punibilidad, en las que por lo mismo no es raro encontrar referencias a que la sensación de seguridad, como interés individual, ha sido afectada. Esta capacidad de tener expectativas respecto de qué bienes e intereses se encuentran en general protegidos frente a terceros puede ser conceptualizada mediante el concepto de orden. Con ello, tratándose en este caso del orden provisto y definido por el Estado, la pena cumple una función de mantenimiento del orden estatal ${ }^{27}$. Esa prestación se deja conceptualizar bajo referencia al concepto de seguridad ${ }^{28}$ : la seguridad caracteriza al mantenimiento de las expectativas que se tienen bajo un orden.

\footnotetext{
${ }^{26}$ Por cierto, en la dogmática penal esto pretende ser contrarrestado por medio del postulado de que solo ciertos estados de cosas posibles pueden ser perseguidos por el derecho penal (teoría del bien jurídico). En este contexto no nos podemos hacer cargo de ello, ya que en la discusión referida al bien jurídico inciden aspectos de crítica y control institucional que deben ser examinados de modo independiente. Basta decir, sin embargo, que la teoría del bien jurídico sufre para estos efectos de los mismos problemas que tienden a aquejar a las teorías de la pena: la fragmentación en la definición de lo que debe ser legitimado hace que sean teorías políticas insuficientes.

${ }^{27}$ Al respecto en detalle Anter, A., Die Macht der Ordnung, Mohr-Siebeck, Tübingen, 2004, pp. 1ss. Entre nosotros, elocuente en este sentido nadie menos que Bustos, J., "Kriminalpolitik und Strafrecht", en Hirsch, H.J., Kaiser, G., y Marquardt, H., Gedächnitsschrift für Hilde Kaufmann, Heidelberg/München/ Landsberg/Berlin, 1986, p. 70: "Dentro del sistema social, la pena siempre ha sido y sigue siendo una confirmación del Estado".

${ }^{28}$ Expresado como crítica general a la teoría de los fines del Estado, decisivamente convincente ya Jellinek, G., Allgemeine Staatslebre, 3. Edición, Wissenschaftliche Buchgesellschaft, Darmstadt, 1960, pp. 227ss., 236ss.; Meyer, G.y Anschütz, G., Lebrbuch des deutschen Staatsrechts, 3. Edición, Duncker \&
} 
La teoría de la pena asume así que el orden es un estado de cosas en sí valioso que debe ser protegido. Para poder proveer una justificación puramente sustantiva de la práctica punitiva, el orden protegido necesita tener un origen prepolítico, ya que de otro modo el argumento perdería toda capacidad de servir de estándar de crítica política: si la legitimidad de la pena no depende del tipo de orden que se trata de proteger, sino que todo orden sirve para legitimar a la pena, entonces por definición su potencial político-crítico es casi nulo. En su origen, en la tradición del derecho natural racional, la asunción del carácter predeterminado del orden civil era definitoria del acercamiento mismo que se adoptaba respecto del derecho: la distinción entre lo prepolítico a cuyo aseguramiento los arreglos políticos y el derecho debieran orientarse y los arreglos políticos mismos (incluyendo el derecho), cuyo objeto es precisamente permitir el aseguramiento de objetivos prepolíticos, era parte esencial del discurso ${ }^{29}$. Al menos desde el siglo XIX, el Estado asume, en cambio, que no se trata solo de la entidad que concentra el poder en un territorio determinado, sino que en él se centralizan las prácticas políticas que determinan la identidad del orden provisto por él ${ }^{30}$. Esto es un hecho histórico esencial en la comprensión de nuestras instituciones que por su relevancia (y por su carácter polémico) tiende a ser pasado por alto: el concepto de Estado designa no solo a un poder territorial soberano, sino a prácticas políticas que, al disponer del poder que posee el Estado, tienen capacidad (ciertamente limitada) de definir el orden de la comunidad.

De este modo, a menos que uno asuma un concepto natural de orden, la concentración de las discusiones referente a legitimidad de la pena en cuestiones instrumentales aparece problemática. Esto puede ser explicado conceptualmente distinguiendo dos funciones que el derecho penal cumple respecto del orden estatal: este tiene una función relativamente evidente de aseguramiento y una menos clara, pero indesmentible, función de constitución de ese orden.

La función de aseguramiento se desprende del concepto mismo de orden. Sociológicamente observado, aquello que se entienda como seguridad depende de aseguramientos sociales previos que conforman nuestras expectativas -el orden-. Como el concepto de seguridad no es más que la contrapartida del concepto sociológico que le antecede y al que sirve (el orden) ${ }^{31}$, la pretensión de legitimar una institución por pura referencia a su condición instrumental a la seguridad no es demasiado elocuente: analíticamente considerado se está simplemente afirmando que el instrumento en cuestión

Humblot, Berlin, 2005, p. 55. En la literatura actual véase sólo la reciente monografía de Wischmeyer, T., Zwecke im Recht des Verfassungsstaates, Mohr Siebeck, Tübingen, 2015, pp. 184ss., con numerosas referencias.

${ }^{29}$ Convincente a este respecto Menke, C., Kritik der Rechte, Suhrkamp, Berlin, 2015, pp. 56ss.

${ }^{30}$ En este sentido ya Heller, H., Gesammelte Schriften Band I, editado por Drath et al., Sijthoff, Leiden, 1971, pp. 248ss., 433ss. El reconocimiento del Estado como forma más desarrollada de la eticidad -a su vez el último estadio en el desarrollo del espíritu objetivo- y, en ese sentido, la concesión de una posición sistemáticamente subordinada a este a la sociedad civil, en los $\S \S 268$ s. de Hegel, G.W.F., Grundlinien der Philosophie des Rechts, en Moldenhauer, E. y Michel, K.M. (eds.), Werke Band 7, Suhrkamp, Frankfurt am Main, 1986, expresa precisamente esta característica.

31 A este respecto véase solo Popitz, H., Prozesse der Machtbildung, Mohr Siebeck, Tübingen, 1969, pp. 16s.; Anter, A., Die Macht der Ordnung, Mohr-Siebeck, Tübingen, 2004, pp 100ss. 
es necesario para asegurar el orden estatal cuando precisamente se quiere legitimar el orden estatal. Lo mismo puede decirse del otro concepto general utilizado por el acercamiento dominante a la teoría de la pena: la necesidad -el derecho penal es legítimo en la medida en que sea necesario para la realización de los fines del Estado- ${ }^{32}$. En tanto concepto central de la racionalidad instrumental -se trata de poder ver una institución como necesaria para alcanzar un fin determinado-, lo necesario depende naturalmente de determinaciones de fines. Si uno asume en los términos más generales posibles (y con ello más neutros políticamente) que instituciones disciplinarias como la pena son necesarias para mantener el orden garantizado por el Estado ${ }^{33}$, entonces la definición de su función depende de la definición de lo que sea ese orden.

Esto permite trazar una conclusión relativamente trivial: si bien la referencia a la función de aseguramiento del derecho penal es crucial para dar cuenta de su identidad, ella es especialmente poco elocuente como estrategia de legitimación de la relación de dominación política que ella asegura.

32 Fundamental en la demostración de la incapacidad del modelo de la racionalidad instrumental bajo reconstrucciones de fines y medios para juzgar adecuadamente organizaciones complejas, Luhmann, N., Zweckbegriff und Systemrationalität, 5. Edición, Suhrkamp, Frankfurt am Main, 1991, pp. 156ss. Ello es asumido también por Hörnle, T., Tatproportionale Strazumessung, Duncker \& Humblot, Berlin, 1999, pp. 112s. En la dogmática penal alemana (y por derivación: hispanoparlante) es usual encontrar reacciones frente a esta crítica -encarnada en la obra de Günther Jakobs- que implican la afirmación de que ella sería "reaccionaria" cuando no "totalitaria”. Al respecto véase solo Silva Sánchez, J.M., La expansión del Derecho penal, 2. Edición, BdeF, Montevideo/Buenos Aires, 2006, pp. 121ss., con ulteriores referencias. Ello se vincula, por cierto, a disputas académicas de escuelas y, por ello, no es siempre racional. Pero es difícil advertir desde un inicio qué puede tener de reaccionario el simple hecho de mostrar que un esquema de control de legitimidad política es insuficiente. Por supuesto: ese esquema tiende a unirse a una cierta orientación liberal y, por ello, sus partidarios sienten que la crítica es una crítica a la ideología liberal, utilizando así la designación retórica de lo que siente como su negación para reaccionar: el totalitarismo. Ello demuestra que aquí no hay más que pura retórica política. Y lo que es peor: esa retórica política esconde el hecho de que el esquema excesivamente simple utilizado para controlar las decisiones políticas hace invisible los problemas de legitimidad sistémicos que afectan al derecho penal en sociedades desiguales.

${ }^{33}$ Esta es una descripción general que puede encontrarse tanto en teorías de la pena ricas de contenido, como en teorías más bien vacías de contenido, que no hacen más que subordinar el sentido de la pena a la protección del orden contingente al que sirven. Así, por ejemplo, Merkel, A., Vergeltungsidee und Zweckgedanke im Strafrecht Verlag von Karl J. Trübner, Strasbourg, 1892, pp. 15s.; Jellinek, G., Die sozialetbische Bedeutung von Recht, Unrecht und Strafe, 2. Edición, Verlag von O. Häring, Berlin, 1908, pp. 60ss, 114ss.; Schmidt, R., Einfübrung in die Rechtswissenschaft, 2. Edición, Felix Meiner, Leipzig, 1923, p. 411; el mismo, Die Aufgaben der Strafrechtspflege, Duncker \& Humblot, Leipzig, 1895, pp. 56ss.; Beling, E., Die Vergeltungsidee und ihre Bedeutung für das Strafrecht, reimpresión, Scientia Verlag, Aalen, 1978, pp. 36s. Completamente explícito Marx, K., "Über die Todestrafe - Herrn Cobdens Pamphlet", en Karl Marx/Friedrich Engels - Werke, Band 8, 3. Edición, Karl Dietz Verlag, Berlin, 1972, pp. 507s. En la discusión contemporánea, este (correcto) vacío de contenido es asumido tanto por algunas variantes de la teoría de la prevención general positiva (especialmente claro en Gärditz, K.F., "Strafbegründung und Demokratieprinzip”, en Der Staat, vol. 49 n 3 2010, pp. 357s.; Appel, I., Verfassung und Strafe, Duncker \& Humblot, Berlin, 1996, pp. 19, 428ss., y en la fórmula generalmente utilizada por el BVerfG para describir el sentido de la pena -véase 27, 18 (29) (derecho administrativo sancionatorio), BVerfGE; 39, 1 (46) (aborto 1); 45, 187 (asesinato y presidio perpetuo); 88, 1 (257) (aborto 2); 120, 224 (241f.) (incesto)- o en su construcción sociologizante en Jakobs, G., Strafrecht Allgemeiner Teil, 2. Edición, De Gruyter, Berlin/New York, 1991, 1/20. 
El argumento es todavía más claro si uno analiza la segunda prestación que cumple el derecho penal respecto del orden estatal: una función de coconstitución. Toda definición de criminalización implica, por una parte, una determinación de que ciertas conductas se encuentran prohibidas o mandadas (estableciendo con ello expectativas correlativas) y una determinación de que esa definición del orden se asegura, entre otras cosas, por medio de castigo por su desconocimiento. Como el derecho penal participa de las definiciones relativas a aquello que debe ser protegido por medio de acción estatal represiva, este tiene necesariamente un carácter constitutivo de parte del contenido del orden estatal $^{34}$. Si esto es así, la referencia al carácter instrumental del derecho penal respecto de la protección del orden estatal es literalmente muda en el aspecto en que la crítica política es más relevante, a saber, en la determinación de aquello que debe ser protegido.

Por supuesto, los defensores de las tradicionales teorías de la pena pueden asumir a este respecto la existencia de ciertas definiciones pertinentes al orden estatal que no son políticamente controvertidas, naturalizarlas y, a partir de ello, naturalizar al derecho penal. En nuestras condiciones políticas actuales puede ser asumido sin demasiados problemas que ningún orden social al que se le quiera prestar reconocimiento no garantizaría la expectativa de no ser asesinado por otro o que sujetaría acciones sexuales plenamente consentidas entre adultos a castigo. Pero esto no hace más que dar cuenta del hecho de que las decisiones políticas tienen su origen muchas veces en desarrollos de la cultura que pasan a ser políticamente pacíficos; justamente en este aspecto es que la crítica política es más bien irrelevante.

En cambio, de entenderse a sí misma como un discurso con capacidad de rendimiento crítico-político, la teoría de la pena debiera poder tener aplicación en las definiciones que importan y que son políticamente relevantes: ¿qué clases de acciones en el mercado son constitutivas de delito? ${ }^{35}$ ¿Qué conductas sexualmente agresivas (pero no coactivas) entre adultos son reprimidas? Las decisiones concernientes a la configuración del orden por medio del derecho penal pueden ser todavía más evidentemente políticas, ya que en ellas no se juegan solo definiciones respecto de lo que se permite en sociedades, sino que muchas veces también deciden en pugnas entre intereses en conflicto. Esto es obvio en la regulación de riesgos en actividades económicas: toda decisión (positiva o negativa) acerca de la criminalización de esas actividades va a implicar necesariamente afectar un interés y garantizar otro. El derecho penal coconstituye aquí el orden estatal, con lo que la referencia al aseguramiento del orden estatal no tiene potencial crítico alguno ${ }^{36}$.

${ }^{34}$ Similar Hassemer,W., Theorie und Soziologie des Verbrechens, Athenäum Verlag, Frankfurt am Main, 1973, pp. 210ss., por referencia a Binding, K., Die Normen und ibre Übertretung. Band I, reimpresión de la cuarta edición, Scientia Verlag, Aalen, 1965, pp. 193ss.

${ }^{35}$ Referido a la politicidad del derecho penal económico también Naucke, W., Der Begriff der politischen Wirtschaftsstraftat, Lit Verlag, Berlin, 2012, pp. 53ss.

36 Aunque no puedo profundizar relacionado con la cuestión aquí, la muestra más clara de la ingenuidad sociológica de la asunción de un discurso sustantivo se encuentra en la observación del modo de constitución de las decisiones de criminalización en el derecho penal contemporáneo. Aunque la cuestión cambia de modo relevante entre países, el derecho penal es en prácticamente toda democracia occidental un ámbito de conflicto, con lo que toda decisión relevante en ámbitos de interés general (criminalización, 
Como el derecho penal y la pena participan de la constitución del orden estatal, la referencia a las prestaciones ("fines") de la pena es especialmente poco elocuente para tematizar su legitimidad política. Ello se extiende así a los conceptos centrales de seguridad y de necesidad que sustentan la argumentación a base de esta estructura: qué es aquello que requiere de seguridad el Estado necesita de una definición previa, a cuyo respecto el postulado de existencia natural es abiertamente inverosímil ${ }^{37}$. Los conceptos cruciales utilizados por la teoría de la pena para tematizar sus definiciones de fines se revelan, por ello, como conceptos estrictamente políticos ${ }^{38}$.

\section{La fisión en la explicación de la legitimidad del orden politico y del instrumento de mantenimiento del orden politico}

El argumento anterior puede ser complementado con un segundo argumento: la construcción de un discurso preocupado específicamente de la legitimación del instrumento de aseguramiento (la pena) genera la impresión de que este se deja justificar con independencia del objeto asegurado (el orden estatal). Políticamente considerado ello no solo es insuficiente sino que además conduce a un conformismo político peligroso.

El argumento puede ser explicado nuevamente por referencia al concepto de seguridad. La seguridad es la prestación que es provista por un orden suficientemente estable $^{39}$. Conceptualmente considerado, un orden requiere de reconocimiento por parte de quienes viven bajo él: sin que las expectativas en cuestión sean internalizadas o al menos respetadas, un orden no es pensable como descripción realista. Esto hace que la constitución de un orden sea, en principio, compleja. Una vez constituido, sin embargo, el orden tiende a mantenerse: en un orden existente quienes viven bajo el orden deben tender, en general, a reconocer el orden -ya que de otra forma no se habría constituido-, con lo que sus propias expectativas de vida se ajustan a este.

no criminalización, descriminalización) es políticamente sensible. A este respecto fundamental ya Gusfield, J., Symbolic Crusade. Status Politics and the American Temperance Movement, 2. Edición,, University of Illinois Press, Urbana/Chicago, 1986, passim; Becker, H., Outsiders. Studies in the Sociology of Deviance, Free Press of Glencoe, New York, 1963, cap. 7. Véase recientemente también Kahan, D., "The Secret Ambition of Deterrence", en Harvard Law Review, vol. 113 n 2, 1999, pp. 413ss. Para las dinámicas de conflicto político (grupos de interés, grupos de identidad, movimientos sociales) que influyen en la configuración del derecho penal véase en general Savelsberg, J., "Knowledge, Domination, and Criminal Punishment", en American Journal of Sociology, vol. 99 n 4, 1994, pp. 911 ss.; Jenness, V., "Explaining Criminalization: From Demography and Status Politics to Globalization and Modernization”, en Annual Review of Sociology, vol. 30, 2004, pp. 147ss.

${ }^{37}$ Entre nosotros, también crítico respecto del desentendimiento de la dependencia política del derecho penal Mir Puig, S., Estado, pena y delito, BdeF, Montevideo/Buenos Aires, 2006, pp. 95s.

${ }^{38}$ El carácter político (incluso "partidista") de toda investigación sobre los fines del Estado ya era resaltado por Jellinek, Allgemeine Staatslehre, G., 3. Edición, Wissenschaftliche Buchgesellschaft, Darmstadt, 1960 , pp. 14s., cuya crítica a la teoría de los fines del Estado (230ss.) tuvo efectos definitivos en la literatura alemana.

39 Véase Popitz, H., Prozesse der Machtbildung, Mohr Siebeck, Tübingen, 1969, pp. 35s.; Anter, A., Die Macht der Ordnung, Mohr-Siebeck, Tübingen, 2004, pp. 100 ss. 
El hecho de que la seguridad sea siempre un valor especialmente popular políticamente puede ser explicado de este modo: todos los sujetos leales al orden es una inversión en este desde el mismo momento en que lo aceptan y se acomodan a sus exigencias. Esta dinámica sociológica hace que todos los órdenes sean políticamente peligrosos pese a su carácter necesario a sociedades complejas: desde el momento en que se imponen, ellos apelan al conformismo ${ }^{40}$.

La teoría de la pena se constituye generalmente, sin embargo, como un discurso relativo a la pura legitimidad de un instrumento de aseguramiento o protección de un orden. La construcción de un discurso filosófico-político de esta clase presupone, sin embargo, la asunción de que tiene sentido preguntarse por la legitimidad del instrumento de aseguramiento sin conectarlo con la legitimidad del objeto asegurado. Al declarar que las definiciones de lo políticamente deseable en la constitución del orden se encuentran fuera de su ámbito de competencia, el modo tradicional de reflexión en la legitimidad de la pena procede exactamente de este modo ${ }^{41}$.

En términos constructivos, ello implica que un instrumento de puro aseguramiento no puede ser juzgado en su legitimidad sin valorar el orden a cuyo aseguramiento contribuye. Si bien hay elementos del instrumento que ciertamente se dejan valorar (ante todo: negativamente) con independencia del contenido del orden -la máxima de necesidad, como exigencia mínima de racionalidad instrumental-, la legitimidad del instrumento depende ante todo del orden al que sirva. Legitimidad del orden estatal y legitimidad de la pena, como instrumento exclusivamente dirigido al aseguramiento de ese orden, son así interdependientes. Como la teoría de la pena asume ser un discurso de la legitimidad independiente del derecho penal, ella pasa necesariamente por alto la interdependencia. Con ello, la asunción de una posición de actor crítico del poder del Estado que asumen constantemente los defensores de distintas clases de teorías de la pena, aparece como infundada ${ }^{42}$ : la estructura misma de la teoría de la pena tiende antes al conformismo que a la crítica política consciente ${ }^{43}$.

${ }^{40}$ Heller, H., Gesammelte Schriften Band I, editado por Drath et al., Sijthoff, Leiden, 1971, p. 433. La dinámica en cuestión subyace a la famosa explicación de la pena de Mead, G.H., "The Psychology of Punitive Justice", en The American Journal of Sociology, vol. 23 n 5, 1918, pp. 584ss., y es ciertamente crucial en los hallazgos sociológicos de Durkheim.

${ }^{41}$ La criminología crítica puede, en su mejor versión, entenderse como una crítica a esta separación que opera en el pensamiento dominante respecto del derecho penal. El trabajo clásico que en algún sentido inaugura esta producida por Rusche, G. y Kirchheimer, O., Punishment E Social Structure, reimpresión primera edición, Russel \& Russel, New York, 1968, pp. 3ss., podía así, antes que el discurso crítico tuviera extensión suficiente para hacerse autorreferente, constatar explícitamente esta ingenuidad en la literatura penal.

${ }^{42}$ Ejemplar Greco, L., Lebendiges und Totes in Feuerbachs Straftheorie, Duncker \& Humblot, Berlin, 2008, pp. 204ss.

43 Similar nadie menos que Marx, K., “Über die Todestrafe - Herrn Cobdens Pamphlet”, en Karl Marx/Friedrich Engels - Werke, Band 8, 3. Edición, Karl Dietz Verlag, Berlin, 1972, pp. 507s. Por referencia a este pasaje de Marx también Murphy, J., Retribution, Justice and Therapy, Reidel Publishing Company, Dordrecht, 1979, pp. 93ss.; Piontkowski, A.A., Hegels Lehre über Staat und Recht und seine Strafrechtstheorie, traducido por John Lekscha, VEB Deutscher Zentralverlag, Berlin (RDA), 1960, pp. 161ff. Entre nosotros 
Un ejemplo puede permitir ilustrar el punto anterior y su aplicación general, esto es, no solo relevante en el ámbito del derecho penal accesorio (en el ámbito anglosajón: de mala probibita) sino también en el derecho penal nuclear (mala in se) ${ }^{44}$ : la criminalización de los delitos contra la propiedad.

Si uno asume que el Estado es competente y, por ello, responsable por la configuración general del mundo social, entonces la existencia, extensión y distribución de la propiedad privada no puede sino ser vista como un hecho político. La criminalización del hurto es una parte del orden normativo así configurado, esto es, no es más que una condición de existencia y aseguramiento de la propiedad privada. Sin hurto, la propiedad privada de bienes muebles probablemente no podría contar con eficacia sociológica. Con ello, la valoración política del hurto es relativa a la valoración política de la propiedad privada $^{45}$. Si la propiedad privada encuentra su justificación en la contribución a la libertad o al bienestar personal de los ciudadanos, entonces el arreglo institucional va a aparecer (mejor: va a ser) legítimo en comunidades en que efectivamente la propiedad privada preste esta contribución a sus miembros. En una sociedad igualitaria sin exclusiones predeterminadas del ámbito de ciudadanos favorecidos, ello probablemente se entienda por sí mismo; la crítica política a la propiedad privada solo podría centrarse en dudar del potencial de esta en sí de contribuir a la liberación, al bienestar o como se le quiera llamar de miembros de una comunidad de humanos. En una sociedad extremadamente desigual $-\mathrm{y}$ ese es ciertamente nuestro caso-, la criminalización del hurto puede ser en cambio designada como parte de un arreglo político tendiente a la dominación por parte de una clase ${ }^{46}$. Ello no tiene lugar porque el hurto (o, mejor, la

así también Mañalich, J.P., "Retribucionismo consecuencialista como programa de ideología punitiva. Una defensa de la teoría de la retribución de Ernst Beling”, en InDret 2015, número 2, pp. 19s.

${ }^{44}$ Le agradezco a Vincent Chiao por advertirme acerca de la idoneidad de este argumento para poner en duda esta asunción.

${ }^{45}$ Esto ciertamente no quiere decir que no sea posible valorar en ocasiones la legitimidad del hurto con relativa independencia del juicio político del orden normativo del que participa. Intentando ejemplificar la importancia política de la teoría de la pena en su estructuración tradicional, Greco, L., Lebendiges und Totes in Feuerbachs Straftheorie, Duncker \& Humblot, Berlin, 2008, p. 205, sostiene que argumentos de prevención general hablarían contra la eficacia del hurto en tiendas y que ello demostraría su relevancia política: la mayor eficacia de la denominada situational prevention y la gran extensión de la cifra negra de hurtos en tiendas permitirían llegar a esta conclusión. A este respecto es por cierto posible afirmar que muchos argumentos hablan a favor de una descriminalización del hurto en tiendas. Pero con toda seguridad ello no se deduce ni de una supuesta completa falta de eficacia preventiva general ni de la cifra negra. La cifra negra de violencia doméstica o de los abusos sexuales no tiende a ser utilizada como argumento a favor de descriminalización, porque no es políticamente convincente argumentar de este modo. En cambio, en casos políticamente polémicos, el argumento de la cifra negra y de la falta de eficacia preventiva general tiende a ser utilizado. El caso central en que la cifra negra es utilizada como argumento de descriminalización no es de hecho el hurto en tiendas, sino el aborto consentido por la mujer. Su inclusión en ámbitos de conflicto político debiera demostrar el punto.

46 En el fondo similar Kleinfeld, J., "Reconstructivism: the Place of Criminal Law in Ethical Life", en Harvard Law Review, vol. 129 n 6, 2016, pp. 1556s. Pero Kleinfeld expresa la interdependencia entre valoración política de un orden y legitimidad de la pena de un modo que ciertamente puede ser comúnmente encontrado, pero que es más bien confuso. De acuerdo con Kleinfeld, uno solo puede ser "reconstructivista" 
propiedad privada) sea en sí algo ilegítimo, sino porque participa de un orden que tiene claros aspectos de ilegitimidad.

Lo anterior permite explicar algo que puede resultar paradójico en el análisis político del derecho penal. La eficacia sociológica de la propiedad privada tiende a ser con toda probabilidad mayor en sociedades igualitarias que en sociedades desiguales ${ }^{47}$. Con ello, la criminalización del hurto es más relevante para el mantenimiento del orden normativo en cuestión precisamente en aquellas sociedades en que este es problemático. Esto es algo que ya al tiempo de Hobbes o Montesquieu podía ser fácilmente reconocido: "sociedades fuertes" necesitan menos derecho penal que sociedades débiles y desiguales; allí donde el derecho penal tiene amplios rasgos de ilegitimidad, este tiende a ser determinante en el mantenimiento del orden estatal. Esta paradoja no debiera ser escondida trazando el punto del modo exactamente inverso a partir de la teoría de la pena y su tendencia a la asunción simple de racionalidad instrumental: como la criminalización es más necesaria en una sociedad desigual, el análisis que rompe la interdependencia va a tender a considerar legítimo el hurto en sociedades desiguales (porque aquí su necesidad para mantener el orden social relativo a la propiedad es evidente) e ilegítimo en sociedades igualitarias (porque su "necesidad preventivo-general no es clara"). Considerada de cerca, sin embargo, la cuestión es exactamente al revés ${ }^{48}$.

Para nuestros propósitos solo es importante constatar que la pretensión de valoración sustantiva de la legitimidad de las leyes penales difícilmente puede ser convincente si se realiza bajo la premisa, favorecida por las teorías de la pena, de valoración independiente de la legitimidad de la pena. Más bien: la legitimidad del sistema penal se confunde

\footnotetext{
-valorar la contribución ética (en términos hegelianos) del derecho penal en la sociedad-en relación con sociedades "decentes". En esto es correcto que la valoración del derecho penal en sociedades desiguales va a tender a ser negativa. Pero de ello no se sigue, en ningún caso, que en sociedades generalmente justas (o "decentes") la valoración del derecho penal deba ser complaciente. El propio caso de Estados Unidos, en el que Kleinfeld construye su argumentación, muestra que los problemas de legitimidad del derecho penal por razones de interdependencia también se reproducen en sociedades decentes.

${ }^{47}$ La cuestión es algo más precisa: la relevancia del mantenimiento coactivo de la propiedad privada aumenta no necesariamente en proporción al aumento objetivo de la desigualdad en su distribución, sino más bien a la percepción que se tenga de esa distribución y, con ello, en la medida en que se actualice una sensación de privación relativa (relative deprivation). Véase a este respecto Haferkamp, H., "Leistungsangleichung und Individualisierung. Unbegriffene Ursachen der Kriminalität und des Strafens in modernen Wohlfahrtstaaten", en el mismo (ed.), Der Woblfahrtsstaat und seine Politik des Strafens, Westdeutscher Verlag, Opladen, 1990, pp. 40ss.; Stack, S., "Income Inequality and Property Crime”, en Criminology, vol. 22 n 2, 1984, pp. 229 ss. La relevancia de este hallazgo ha tendido, sin embargo, a disminuir: una sociedad podía soportar altos niveles de desigualdad en la medida en que no hubiera conciencia de ello y de su relevancia política. Con la masificación de la educación escolar, esa falta de conciencia ha tendido a desaparecer.

48 Un argumento similar puede encontrarse en Garland, D., Punishment and Modern Society, Oxford University Press, Oxford/New York, 1990, pp. 3ss.: las instituciones tendrían en general "efectos oscuros y reaseguradores"; pensar solo "dentro de las instituciones" al evaluarlas políticamente tiende a verse acompañado de un oscurecimiento de su contingencia y, con ello, con asunción acrítica de varios de sus (contingentes) rasgos centrales. En general respecto de esta tendencia en el pensamiento institucional Selznick, P., The Moral Commonwealth, University of California Press, Berkeley/Los Angeles/Oxford, 1992, pp. 244ss.
} 
en parte con la legitimidad del sistema estatal al que sirve ${ }^{49}$. Esto da cuenta de la falsa promesa que la teoría de la pena cumple en el área política: si ella es vista como una teoría política aplicada, su rendimiento es mucho menor a los problemas que ella produce.

\section{ACERCA DE LA COMPLEJIDAD DE LA DisCusión DE LA LEGITIMIDAD DE LA PENA}

Las críticas que hemos efectuado a la tradición de discusión respecto de la legitimidad política de la pena no implican, por cierto, declarar que la pretensión que subyace a esa discusión -evaluación de legitimidad política del sistema penal- sea problemática. Al contrario: esa pretensión se encuentra justificada; el derecho penal es políticamente relevante. El problema no se encuentra en la pregunta, sino en las respuestas que tienden a entregarse en la "teoría de la pena": o bien condiciones de legitimidad moral del castigo o bien definición fija de fines del Estado y, a partir de ello, tendencia a centrarse en discutir exclusivamente por la idoneidad instrumental del derecho penal -con la tendencia a pasar por alto justamente los aspectos políticamente relevantes del derecho penal.

Lo anterior no quiere decir, por cierto, que argumentos que puedan ser conectados con determinadas teorías de la pena -ante todo, pero no exclusivamente, de prevención- no tengan nunca relevancia política. Reformas político-criminales pueden basarse efectivamente en consideraciones de prevención pese a que ciertos modos de (intentar) producir prevención puedan ser al mismo tiempo políticamente conflictivos; en esto no hay nada criticable. El modo tradicional de teorizar referente a la legitimidad de la pena crea, sin embargo, la ilusión de que las decisiones políticas se dejan justificar a base de una sola clase de argumentos políticos. Incluso un defensor especialmente conocido de una clase de teorías de la pena en la actualidad -Anthony Duff- puede expresar de modo especialmente claro el punto:

It would be rash to posit a single, determinate purpose or function as the purpose or function of criminal law. That would be misguided as an interpretive claim about existing systems of criminal law: we cannot understand a set of institutional practices with as a long and complex a history as those that constitute the criminal law of any developed polity in terms of a single purpose or function. It might seem more tempting to posit some unitary purpose as a matter of normative theory: to argue, for instance, that the purpose of criminal law is to maximize dominion, or to achieve retributive justice by securing the punishment of moral wrongdoers. I cannot argue the point here, but believe that such normative claims are also untenable: any plausible normative theory of criminal law will be complex and messy, positing a collection of purposes that cannot fit together into a tidy whole ${ }^{50}$.

49 Así también Ristroph, A., "Conditions of Legitimate Punishment”, en Flanders, C. y Hoskins, Z. (eds.), The New Philosophy of Criminal Law, London: Rowman \& Littlefeld, 2015, pp. 82ss.

50 Duff, R.A., "Responsibility, citizenship and criminal law”, en el mismo y Stuart Green (eds.), Philosophical Foundations of Criminal Law, Oxford University Press, Oxford/New York, 2011, pp. 125s. 
La crítica puede ser expresada en otros términos: desde el momento en que el derecho penal es dejado a disposición política -y en una democracia ello no puede ser sino así-, el lenguaje de crítica y legitimación política debe asumir su lógica. Desde el punto de vista del legislador, el derecho penal no puede sino aparecer como un instrumento en el cumplimiento de los fines que este se fije. En esto no hay diferencias relevantes entre derecho penal, derecho administrativo e incluso, con limitaciones, derecho privado: estabilización de expectativas mediante confirmación y prevención es algo que se encuentra presente en decisiones tomadas por el legislador en todos estos ámbitos ${ }^{51}$. Podemos, por cierto, discutir acerca de los fines legítimos que puede perseguir el Estado, pero las limitaciones del lenguaje típicamente utilizado en la teoría de la pena no pueden ser sino una molestia en este ámbito. Podemos también discutir por la idoneidad del derecho penal para perseguir fines legítimos, así como relativo a la posibilidad de utilizar medios menos lesivos. Seguro es solo una cosa: nuestras discusiones político-criminales son mucho más complejas, con razón, de lo que el esquema tendiente a la unidad de la teoría de la pena tiende a expresar.

\section{BIBLIOGRAFÍA}

ACHTER, V., Geburt der Strafe, Vittorio Klostermann, Frankfurt am Main, 1951.

Anter, A., Die Macht der Ordnung, Mohr-Siebeck, Tubinga, 2004.

Appel, I., Verfassung und Strafe, Duncker \& Humblot, Berlín, 1996.

Bauer, A., Die Warnungstheorie, reimpresión, Keip Verlag, Goldbach, 1996.

Bauer, A., Lehrbuch des Strafrechts, reimpresión, Keip Verlag, Goldbach, 1996.

Becker, H., Outsiders. Studies in the Sociology of Deviance, Free Press of Glencoe, New York, 1963.

Beling, E., Die Vergeltungsidee und ihre Bedeutung für das Strafrecht, reimpresión, Scientia Verlag, Aalen, 1978.

Binder, G., "Punishment Theory: Moral or Political”, en Buffalo Criminal Law Review, vol. 5, 2002, pp. 321-72.

Binding, K., Die Normen und ibre Übertretung. Band I, reimpresión de la cuarta edición, Scientia Verlag, Aalen, 1965.

BöCKenförde, E.W., Recht, Staat, Freiheit, edición extendida, Suhrkamp, Frankfurt am Main, 2006.

Brudner, A., Punishment and Freedom, Oxford University Press, Oxford/New York, 2009.

Brunner, O., Land und Herrschaft, 5. Edición, Wissenschaftliche Buchgesellschaft, Darmstadt, 1984.

Bustos Ramírez, J., "Kriminalpolitik und Strafrecht”, en Hirsch, H.J., Kaiser, G., y Marquardt, H., Gedächnitsschrift für Hilde Kaufmann, De Gruyter, Heidelberg/München/Landsberg/ Berlin, 1986, pp. 69-88.

Chiao, Vincent, "What is the Criminal Law for?", en Law and Philosophy, vol. 35, 2016, pp. 137-63.

Duff, R.A., "Penance, Punishment and Community", en Punishment and Society, vol. 5, 2003, pp. 295-312.

\footnotetext{
${ }^{51}$ Así también Gärditz, K.F., Staat und Strafrechtspflege, Ferdinand Schöningh, Paderborn, 2015, pp. 46ss.
} 
Duff, R.A., "Responsibility, citizenship and criminal law", en el mismo y Stuart Green (eds.), Philosophical Foundations of Criminal Law, Oxford University Press, Oxford/New York, 2011, pp. 125-48.

Duff, R.A., Farmer, L., Marshall, S.E., Renzo, M., y Tadros, V., "Introduction. Towards a Theory of Criminalization?", en los mismos, Criminalization. The Political Morality of the Criminal Law, Oxford University Press, Oxford/New York, 2014, pp. 1-53.

Feuerbach, P.J.A., Lebrbuch des gemeinen in Deutschland gültigen peinlichen Rechts, reimpresión, Scientia Verlag, Aalen, 1986.

Feuerbach, P.J.A., Revision der Grundsätze und Grundbegriff des positiven peinlichen Rechts, reimpresión, Scientia Verlag, Aalen, 1986.

Gärditz, K.F., Staat und Strafrechtspflege, Ferdinand Schöningh, Paderborn, 2015.

GäRDITZ, K.F., “Strafbegründung und Demokratieprinzip”, en Der Staat, vol. 49, 2010, pp. 331-67.

Garland, D., Punishment and Modern Society, Oxford University Press, Oxford/New York, 1990.

Garland, D., The Culture of Control, Oxford University Press, Oxford/New York, 2001.

Greco, L., Lebendiges und Totes in Feuerbachs Straftheorie, Duncker \& Humblot, Berlin, 2009.

Greco, L., "Verfassungskonformes oder legitimes Strafrecht? Zu den Grenzen einer verfassungsrechtlichen Orientierung der Strafrechtswissenschaft", en Brunhöber et al. (eds.), Strafrecht und Verfassung, Nomos, Baden-Baden, 2013, pp. 13-36.

Gusfield, J., Symbolic Crusade. Status Politics and the American Temperance Movement, 2. Edición, University of Illinois Press, Urbana/Chicago, 1986.

Haferkamp, H., "Leistungsangleichung und Individualisierung. Unbegriffene Ursachen der Kriminalität und des Strafens in modernen Wohlfahrtstaaten”, en el mismo (ed.), Der Woblfabrtsstaat und seine Politik des Strafens, Westdeutscher Verlag, Opladen:, 1990, pp. 7-62.

Hälschner, H., Das gemeine Deutsche Strafrecht. Band I: Die allgemeinen strafrechtlichen Lehren, reimpresión, Keip Verlag, Goldbach, 1997.

Hassemer, W., Theorie und Soziologie des Verbrechens, Athenäum Verlag, Frankfurt am Main, 1973.

Hassemer, W., Steinert, H., y Treiber, H., "Soziale Reaktion auf Abweichung und Kriminalisierung durch den Gesetzgeber”, en Hassemer, W. y Lüderssen, K. (eds.), Sozialwissenschaften im Studium des Rechts. Band III: Strafrecht, C.H. Beck, München, 1978, pp. 1-66.

Hegel, G.W.F., Grundlinien der Philosophie des Rechts, en Moldenhauer, E., y Michel, K.M. (eds.), Werke Band 7, Suhrkamp, Frankfurt am Main, 1986.

Heller, H., Gesammelte Schriften Band I, editado por Drath et al., Sijthoff, Leiden, 1971.

Hobbes, T., Leviathan, J.M. Dent \& Sons, London, 1914.

Hörnle, T., Tatproportionale Strazumessung, Duncker \& Humblot, Berlin, 1999.

Husak, D., "Does the State have a Monopoly to Punish Crime?", en Flanders, C., y Hoskins, Z. (eds.), The New Philosophy of Criminal Law, London: Rowman \& Littlefeld, 2016, pp. 97-112.

Husak, D., Overcriminalization, Oxford University Press, Oxford/New York, 2008.

Jakoвs, G., Strafrecht Allgemeiner Teil, 2. Edición, De Gruyter, Berlin/New York, 1991.

JARCKE, K.E., Handbuch des deutschen Strafrechts, reimpresión, Keip Verlag, Goldbach, 1996.

Jellinek, G., Allgemeine Staatslehre, 3. edición, Wissenschaftliche Buchgesellschaft, Darmstadt, 1960.

Jellinek, G., Die sozialethische Bedeutung von Recht, Unrecht und Strafe, 2. Edición, Verlag von O. Häring, Berlin, 1908.

Jenness, V., "Explaining Criminalization: From Demography and Status Politics to Globalization and Modernization", en Annual Review of Sociology, vol. 30, 2004, pp. 147-71.

Kahan, D., "The Secret Ambition of Deterrence", en Harvard Law Review, vol. 113, 1999, pp. 413-500. 
KasPaR, J., Verbältnismäßigkeit und Grundrechtsschutz im Präventionsstrafrecht, Nomos, BadenBaden, 2014.

Kleinfeld, J., "Reconstructivism: the Place of Criminal Law in Ethical Life", en Harvard Law Review, vol. 129, 2016, pp. 1485-1565.

LorCa, R., "The Presumption of Punishment: A Critical Review of its Early Modern Origins", en Canadian Journal of Law E Jurisprudence, vol. 29, 2016, pp. 385-402.

Loughlin, M., Foundations of Public Law, Oxford University Press, Oxford/New York, 2010.

LuHManN, N., Zweckbegriff und Systemrationalität, 5. Edición, Suhrkamp, Frankfurt am Main, 1991.

MaÑalich, Juan Pablo, "Retribucionismo consecuencialista como programa de ideología punitiva. Una defensa de la teoría de la retribución de Ernst Beling", en InDret 2-2015.

Marx, K., "Über die Todestrafe - Herrn Cobdens Pamphlet", en Karl Marx/Friedrich Engels Werke, Band 8, 3. Edición, Karl Dietz Verlag, Berlin (RDA), 1972, pp. 506-13.

Mead, G.H.., "The Psychology of Punitive Justice", en The American Journal of Sociology, vol. 23, 1918, pp. 577-602.

Menke, C., Kritik der Rechte, Suhrkamp, Berlin, 2015.

Merkel, A., Vergeltungsidee und Zweckgedanke im Strafrecht, Verlag von Karl J. Trübner, Strasbourg, 1892.

Meyer, G., y Anschütz, G. Lehrbuch des deutschen Staatsrechts, 3. edición, Duncker \& Humblot, Berlin, 2005.

Mir Puig, S., Estado, penal y delito, BdeF, Montevideo/Buenos Aires, 2006.

Mommsen, T., Römisches Strafrecht, Duncker \& Humblot, Leipzig, 1899.

Murphy, J., Retribution, Justice and Therapy, Reidel Publishing Company, Dordrecht, 1979.

Murphy, J., "Does Kant Have a Theory of Punishment?", en Columbia Law Review, vol. 87, 1987, pp. 509-32.

Naucke, Wolfgang, Der Begriff der politischen Wirtschaftsstraftat, Lit Verlag, Berlin, 2012.

Naucke, Wolfgang, "Fragen an Feuerbachs Staatsbegriff”, en Gröschner, R.y Haney, G. (eds.), Die Bedeutung P.J.A. Feuerbachs (1775-1833) für die Gegenwart, Franz Steiner Verlag, Wiesbaden, 2003, pp. 41-49.

Piontkowski, A.A., Hegels Lehre über Staat und Recht und seine Strafrechtstheorie, traducción de John Lekscha, VEB Deutscher Zentralverlag, Berlin (RDA), 1960.

Popitz, H., Prozesse der Machtbildung, Mohr Siebeck, Tübingen, 1969.

Ramsay, P., "The Dialogic Community at Dusk", en Critical Analysis of Law, vol. 1 n 2, 2014, pp. 316-332.

Ramsay, P., "The Responsible Subject as Citizen: Criminal Law, Democracy and the Welfare State”, en The Modern Law Review, vol. 69, 2006, pp. 29-58.

ReINHARD, W., Geschichte der Staatsgewalt, C.H. Beck, München, 1999.

Riggsby, A., Roman Law and the Legal World of the Romans, Cambridge University Press, New York, 2010.

Ristroph, A., "Conditions of Legitimate Punishment", en Flander, C. y Hoskins, Z., The New Philosophy of Criminal Law, Rowman \& Littlefeld, London, 2015, pp. 79-95.

RüPING, H., y Jerouscheck, G., Grundriss der Strafrechtsgeschichte, 5. Edición, C.H. Beck, München, 2007.

Rusche, G.y Kirchheimer, O., Punishment E Social Structure, reimpresión de la primera edición, Russel \& Russel, New York, 1968.

Savelsberg, J., "Knowledge, Domination, and Criminal Punishment", en American Journal of Sociology, vol. 99, 1994, pp. 911-43.

SchмiDt, E., Einführung in die Geschichte der deutschen Strafrechtspflege, 2. Edición, Vandenboeck \& Ruprecht, Göttingen, 1951. 
Schmidt, R., Die Aufgaben der Strafrechtspflege, Duncker \& Humblot, Leipzig, 1895.

SchmidT, R., Einführung in die Rechtswissenschaft, 2. Edición, Felix Meiner, Leipzig, 1923.

Selznick, P., The Moral Commonwealth, University of California Press, Berkeley/Los Angeles/ Oxford, 1992.

Silva Sánchez, J.M., La expansión del Derecho penal, 2. Edición, BdeF, Montevideo/Buenos Aires, 2006.

StaCK, S., "Income Inequality and Property Crime", en Criminology, vol. 22, 1984, pp. 229-57.

Tadros, V., The Ends of Harm, Oxford University Press, Oxford/New York, 2011.

Thorburn, M., "Criminal Law as Public Law”, en Duff, R.A., y Green, S. (eds.), Philosophical Foundations of Criminal Law, Oxford University Press, Oxford/New York, 2013, pp. 21-47.

Tonry, M., "Punishment", en el mismo (ed.), The Oxford Handbook of Crime and Criminal Justice, Oxford University Press, New York, 2011, pp. 95-125.

von Grolman, K.,, Grundsätze der Criminalrechtswissenschaft, reimpresión, Keip Verlag, Goldbach, 1996.

von Hirsch, A., y Ashworth, A., Proportionate Sentencing, Oxford University Press, Oxford/ New York, 2005.

von Mohl, R., Die Polizei-Wissenschaft nach den Grundsätzen des Rechtsstaates. Dritter Band: System der Präventiv-Justiz, 3. Edición, Verlag der H. Laupp'schen Buchhandlung, Tübingen, 1866.

von Wächter, C.G., Lehrbuch des Römisch - Teutschen Strafrechts, reimpresión, Keip Verlag, Goldbach, 2001.

Waldron, J., Political political theory, Harvard University Press, Cambridge/London, 2016.

Weber, M., Wirtschaft und Gesellschaft, editado por Johannes Winckelmann, 5. Edición, Mohr, Tübingen, 1980.

Wischmeyer, T., Zwecke im Recht des Verfassungsstaates, Mohr Siebeck, Tübingen, 2015.

Zabel, B., "Die ordnungspolitische Funktion des Strafrechts", en Zeitschrift für die gesamte Strafrechtswissenschaft, vol. 120, 2008, pp. 68-106.

ZürCHer, T., Legitimation von Strafe, Mohr Siebeck, Tübingen, 2014. 
